\title{
Haemoglobin and red cell counts in leptospirosis patients infected with different serovars
}

\author{
Scott Benjamin Craig ${ }^{[1],[2], ~ L e e ~ D o u g l a s ~ S m y t h e ~}{ }^{[1],[2], ~ G l e n n ~ C h a r l e s ~ G r a h a m ~}{ }^{[2],[3],}$ \\ Mary-Anne Burns ${ }^{[1]}$, Jamie Lee McMahon ${ }^{[1]}$, Michael Francis Dohnt ${ }^{[1]}$, \\ Suhella Mohan Tulsiani ${ }^{[1]}$ and David Brian McKay ${ }^{[2]}$
}

[1]. Communicable Diseases Unit, Queensland Health Forensic and Scientific Service, WHO/OIE/FAO Collaborating Centre for Reference and Research on Leptospirosis, Archerfield, Queensland, Australia. [2]. Faculty of Science, Health and Education, University of the Sunshine Coast, Sippy Downs, Queensland, Australia. [3]. Organic Chemistry Department, Chemical Analysis Unit, Queensland Health Forensic and Scientific Service, Archerfield, Queensland, Australia.

\begin{abstract}
Introduction: The aim of the study was to compare haemoglobin and red cell counts between patients known to be infected with a range of leptospiral serovars. Methods: The study retrospectively compared the haemoglobin and red cell count results from the first blood samples taken from 207 patients at presentation to a Queensland Health hospital. Results: Significant differences were observed in haemoglobin and red cell counts in those infected with Leptospira interrogans serovars Szwajizak and Canicola when compared with most of the other serovars. Conclusions: These findings suggest that haemoglobin and red cell counts may be useful in differentiating leptospiral serovars in leptospirosis patients.
\end{abstract}

Keywords: Leptospirosis. Haemoglobin. Red cell count.

Leptospirosis is an emerging bacterial zoonotic disease of worldwide importance. Patients with leptospirosis can present with a wide clinical spectrum with haematological manifestations often apparent ${ }^{1}$. Infections in humans can vary from being mild, where flu-like symptoms are exhibited, to acute, where, in extreme cases, the onset of renal and hepatic failure can occur ${ }^{2}$. The disease can progress to Weil's disease (also referred to as severe icteric leptospirosis with renal failure), which has a mortality rate of $5-50 \%{ }^{3,4}$.

Leptospires are motile, flexible, helical aerobic spirochaetes, of which some members are considered as non-pathogenic while the remainder are known pathogens of man and animals ${ }^{5}$. Leptospires enter the host when mucous membranes or abraded skin comes in contact with contaminated environmental sources $^{6}$. Transmission to humans can occur from direct contact with the urine of a mammalian host or indirectly through contact with contaminated water, soil, or infected body fluids or tissues of carrier animals ${ }^{6}$.

A number of reviews and studies have been undertaken in recent years to better understand the value of laboratory findings for the diagnosis and management of leptospirosis? ${ }^{7}$. A retrospective review of 34 patients with leptospirosis, admitted in Pontchaillou Hospital located in metropolitan France, observed

Address to: Prof. Scott Benjamin Craig. Faculty of Science, Health and Education/USC. Sippy Downs Drive, Sippy Downs, Queensland, 4556, Australia.

Fax: 617 3274-9175

e-mail: Scott_Craig@health.qld.gov.au

Received 07 March 2011

Accepted 18 May 2011 that $85 \%$ of leptospirosis patients were lymphopenic and concluded that lymphopenia is a common feature of leptospirosis ${ }^{8}$. In response to this finding, 253 leptospirosis patient cases were reviewed in Salvador, Brazil, and it was conversely observed that only $17 \%$ of patients were lymphopenic at admission 9 Additionally, the authors suggested that environmental factors and the different distribution of leptospiral serovars may account for the differences observed in the frequency of lymphopenia ${ }^{9}$. The most common serovar in Salvador, Brazil is Leptospira interrogans serovar Copenhageni ${ }^{10,11}$, while in the Pontchaillou Hospital study, the most common was Leptospira interrogans serovar Grippotyphosa ${ }^{8}$. Both studies failed to report the frequency of lymphopenia across serovars.

In response to this knowledge gap, recent research reported lymphopenia during the acute phase of leptospiral infections appears common across the majority of pathogenic serovars screened for in Australia, with Leptospira borgpetersenii serovar Arborea, L. borgpetersenii serovar Hardjo, and L. interrogans serovar Copenhageni being the possible exceptions ${ }^{12}$. While there is now a slow accumulation of published data in relation to lymphocyte counts between different infecting leptospiral serovars, data on other haematological markers between infecting serovars appears to elude the research literature. The aim of this study was to compare and identify haemoglobin and red cell counts that were different between patients infected with different leptospiral serovars at first presentation.

The study protocol was approved by the Human Ethics Committee from Queensland Health Forensic and Scientific Service (Approval Number 08-001/12) and the Human Ethics Research Committee from the University of the Sunshine Coast (Approval Number A/08/155). 
A total of 207 leptospirosis patients, all male between 18 and 75 years of age, were identified and investigated retrospectively over a 10-year period (1999-2009) using the patient database at the World Health Organization (WHO)/ Food and Agriculture Organization (FAO)/ World Organisation for Animal Health (OIE) Collaborating Center for Reference and Research on Leptospirosis, Brisbane. Leptospirosis was confirmed through the isolation of leptospires from blood cultures in EllinghausenMcCullough-Johnson-Harris (EMJH) media, detection by real-time polymerase chain reaction (PCR), or serology with a microscopic agglutination test (MAT) showing a greater than fourfold rise in titre on follow-up from the initial presentation. At the time of presentation, all patients were MAT nonreactive, indicating acute phase of the disease. Patients presenting with significant respiratory distress, indicated by diffuse alveolar haemorrhage and/or acute liver or renal failure requiring admission to an intensive care unit or high dependency unit, were excluded from the study. Infecting serovar was determined from isolates using the cross-agglutination absorption test (CAAT) or from serum by MAT. Both the CAAT and MAT have high specificity for identifying infecting serovars circulating in Australia.

Common diseases causing pyrexia in Australia, such as dengue fever, Ross River fever, infections by Barmah Forest Virus, and rickettsial species, were excluded through serology, while infections with pathogenic Staphylococcus spp., Meningococcus spp., Pseudomonas spp., Haemophilus spp., and other anaerobes were excluded by negative blood cultures.

Pathology results reported were those from the first sample collected at the initial presentation at a Queensland Health Hospital. Haemoglobin and red cell counts were investigated in this study. The findings between the different serovar infected groups were compared firstly using between groups analysis of variance (ANOVA). Derived $F$ statistics $<0.05$ were followed up with post hoc $t$-tests using the $t$-tests statistical function in Microsoft Excel. Haemoglobin and red cell counts between the groups were considered significant for $\mathrm{p}$ values $<0.05$.

The haematological marker results from patients infected with different serovars are presented in Table 1. Significant differences were observed (Table 1) in haemoglobin $(F=2.67 ; \mathrm{p}=0.004)$ and red cell $(F=2.75 ; \mathrm{p}=0.003)$ counts across the serovars.

Follow-up investigations of the mean haemoglobin concentration between the groups of patients infected with different serovars revealed that the higher mean concentration of haemoglobin observed in the serovar Szwajizak infected group was significantly different to most of the other serovars except serovar Celledoni (Table 2). The mean concentration of haemoglobin in patients infected with the serovar Canicola was significantly lower than that observed in the group infected with the serovar Celledoni $(131.29 \mathrm{~g} / \mathrm{L}$ versus $154.17 \mathrm{~g} / \mathrm{L}, \mathrm{p}=0.03)$. Significant differences in the mean haemoglobin concentration were also observed between groups of patients infected with serovars: Canicola and Hardjo $(131.29 \mathrm{~g} / \mathrm{L}$ versus $146.29 \mathrm{~g} / \mathrm{L}$, $\mathrm{p}=0.03)$; Canicola and Robinsoni $(131.29 \mathrm{~g} / \mathrm{L}$ versus $145.56 \mathrm{~g} / \mathrm{L}$, $\mathrm{p}=0.02)$; Canicola and Tarassovi $(131.29 \mathrm{~g} / \mathrm{L}$ versus $145.30 \mathrm{~g} / \mathrm{L}$, $\mathrm{p}=0.04)$; and Canicola and Zanoni $(131.29 \mathrm{~g} / \mathrm{L}$ versus $147.34 \mathrm{~g} / \mathrm{L}$, $\mathrm{p}=0.02$ ).

Similarly, follow-up investigations of the mean red cell count (RCC) between the groups of patients infected with different serovars revealed that the higher mean RCC observed in the serovar Szwajizak infected group was significantly different to most of the other serovar infected groups except for groups infected with serovar Celledoni (Table 3). Significant differences in the mean RCC were also observed between the: Kremastos and Canicola infected groups $\left(4.81 \times 10^{9} / \mathrm{L}\right.$ versus $4.41 \times 10^{9} / \mathrm{L}$,

TABLE 1 - Haemoglobin and red cell counts as a function of infecting serovar

\begin{tabular}{|c|c|c|c|c|c|c|}
\hline \multirow[b]{2}{*}{ Serovar } & \multicolumn{3}{|c|}{$\mathrm{Hb}^{\mathrm{a}}$} & \multicolumn{3}{|c|}{$\mathrm{RCC}^{\mathrm{b}}$} \\
\hline & $\mathrm{N}$ & Mean & SE & $\mathrm{N}$ & Mean & SE \\
\hline Leptospira borgpetersenii serovar Arborea & 14 & 142.79 & 19.74 & 14 & 4.80 & 0.53 \\
\hline Leptospira interrogans serovar Canicola & 7 & 131.29 & 12.78 & 7 & 4.41 & 0.41 \\
\hline Leptospira weilii serovar Celledoni & 6 & 154.17 & 18.47 & 6 & 4.96 & 0.57 \\
\hline Leptospira interrogans serovar Kremastos & 15 & 143.53 & 15.54 & 15 & 4.81 & 0.36 \\
\hline Leptospira interrogans serovar Robinsoni & 18 & 145.56 & 12.38 & 18 & 4.84 & 0.36 \\
\hline Leptospira interrogans serovar Szwajizak & 8 & 160.38 & 4.53 & 8 & 5.49 & 0.35 \\
\hline Leptospira borgpetersenii serovar Tarassovi & 10 & 145.30 & 11.76 & 10 & 4.88 & 0.37 \\
\hline Leptospira weilii serovar Topaz & 9 & 141.22 & 9.34 & 9 & 4.68 & 0.23 \\
\hline
\end{tabular}

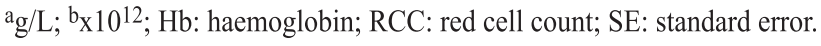


TABLE 2 - $\mathrm{p}$ values for mean pairwise serovar $\mathrm{Hb}$ comparisons

\begin{tabular}{|c|c|c|c|c|c|c|c|c|c|c|c|}
\hline & Arborea & Australis & Canicola & Celledoni & Hardjo & Kremastos & Robinsoni & Szwajizak & Topaz & Tarassovi & Zanoni \\
\hline Arborea & - & 0.9 & 0.12 & 0.24 & 0.6 & 0.91 & 0.65 & 0.006 & 0.8 & 0.7 & 0.42 \\
\hline Australis & - & - & 0.07 & 0.17 & 0.33 & 0.75 & 0.31 & $<0.001$ & 0.81 & 0.44 & 0.03 \\
\hline Canicola & - & - & - & 0.03 & 0.03 & 0.07 & 0.03 & $<0.001$ & 0.11 & 0.04 & 0.02 \\
\hline Celledoni & - & - & - & - & 0.37 & 0.25 & 0.32 & 0.46 & 0.15 & 0.33 & 0.41 \\
\hline Hardjo & - & - & - & - & - & 0.62 & 0.88 & 0.003 & 0.31 & 0.85 & 0.8 \\
\hline Kremastos & - & - & - & - & - & - & 0.68 & 0.001 & 0.65 & 0.74 & 0.38 \\
\hline Robinsoni & - & - & - & - & - & - & - & 0.002 & 0.32 & 0.96 & 0.6 \\
\hline Szwajizak & - & - & - & - & - & - & - & - & 0.001 & 0.003 & $<0.001$ \\
\hline Topaz & - & - & - & - & - & - & - & - & - & 0.41 & 0.1 \\
\hline Tarassovi & - & - & - & - & - & - & - & - & - & - & 0.15 \\
\hline Zanoni & - & - & - & - & - & - & - & - & - & - & - \\
\hline
\end{tabular}

$\mathrm{Hb}$ : Haemoglobin.

TABLE 3 - $p$ values for mean pairwise serovar red cell count comparisons

\begin{tabular}{|c|c|c|c|c|c|c|c|c|c|c|c|}
\hline & Arborea & Australis & Canicola & Celledoni & Hardjo & Kremastos & Robinsoni & Szwajizak & Topaz & Tarassovi & Zanoni \\
\hline Arborea & - & 0.83 & 0.08 & 0.58 & 0.76 & 0.94 & 0.8 & 0.002 & 0.46 & 0.65 & 0.81 \\
\hline Australis & - & - & 0.06 & 0.46 & 0.58 & 0.71 & 0.51 & $<0.001$ & 0.44 & 0.41 & 0.98 \\
\hline Canicola & - & - & - & 0.08 & 0.05 & 0.04 & 0.03 & $<0.001$ & 0.15 & 0.03 & 0.07 \\
\hline Celledoni & - & - & - & - & 0.74 & 0.58 & 0.66 & 0.07 & 0.3 & 0.78 & 0.45 \\
\hline Hardjo & - & - & - & - & - & 0.78 & 0.91 & 0.005 & 0.3 & 0.91 & 0.55 \\
\hline Kremastos & - & - & - & - & - & - & 0.81 & $<0.001$ & 0.28 & 0.63 & 0.66 \\
\hline Robinsoni & - & - & - & - & - & - & - & $<0.001$ & 0.17 & 0.78 & 0.44 \\
\hline Szwajizak & - & - & - & - & - & - & - & - & $<0.001$ & 0.002 & 0.003 \\
\hline Topaz & - & - & - & - & - & - & - & - & - & 0.16 & 0.38 \\
\hline Tarassovi & - & - & - & - & - & - & - & - & - & - & 0.37 \\
\hline Zanoni & - & - & - & - & - & - & - & - & - & - & - \\
\hline
\end{tabular}

$\mathrm{p}=0.04)$; Robinsoni and Canicola infected groups $\left(4.84 \times 10^{9} / \mathrm{L}\right.$ versus $\left.4.41 \times 10^{9} / \mathrm{L}, \mathrm{p}=0.03\right)$; and Tarassovi and Canicola infected groups $\left(4.88 \times 10^{9} / \mathrm{L}\right.$ versus $\left.4.41 \times 10^{9} / \mathrm{L}, \mathrm{p}=0.03\right)$.

In humans, the occurrence of lymphopenia during the acute phase of leptospirosis was reported as being common across the majority of pathogenic serovars screened for in Australia ${ }^{12}$. The only exceptions identified by the study were L. borgpetersenii serovars Arborea and Hardjo and L. interrogans serovar Copenhageni ${ }^{12}$. There are significant published data in relation to lymphocyte counts between different infecting serovars, while there is a paucity of data about variation of other haematological markers in the literature. The aim of the study was to compare haemoglobin and red cell counts between patients known to be infected with a range of leptospiral serovars at their first presentation.

The statistical differences observed between serovars in relation to red cell indices, such as $\mathrm{Hb}$ and $\mathrm{RCC}$, are not unexpected, as erythroid hypoplasia has been reported in leptospirosis ${ }^{13}$. Patients infected with serovar Szwajizak presented with the highest mean $\mathrm{Hb}$ and $\mathrm{RCC}$, and these findings may be due to a less direct toxic effect on the erythroid progenitor cells but may also reflect a lower impact of the serovar on the integrity of the vascular system or a combination of both. Conversely, patients infected with serovar Canicola presented with the lowest mean $\mathrm{Hb}$ and $\mathrm{RCC}$, and this observation may be due to a more direct toxic effect on the erythroid progenitor cells or may also reflect a higher impact of the serovar on the integrity of the vascular system or a combination of both.

Interleukin 3 produced by lymphocytes is an important cytokine in erythrocyte haemopoeisis ${ }^{14,15}$, and based on this, it may be postulated that the lymphopenia frequently observed in leptospirosis may also affect red cell indices investigated here $^{12}$. However, lymphopenia has been observed in all those infected with serovar Szwajizak, which would suggest that red cell indices would not be higher in this group ${ }^{12}$.

Further studies investigating erythropoietin, vitamin B12, serum folate, and red cell folate are required to determine if these markers underpin the differences observed in red cell indices between the different infecting serovars. The results of such studies may also provide valuable therapeutic insight for the treatment or management of the disease in patients. Further studies are also required to compare and identify other 
haematological markers that are different between patients infected with different leptospiral serovars at first presentation. Such studies may also provide valuable therapeutic insights into treating the disease.

In conclusion, this is the first study to identify the differences in $\mathrm{Hb}$ and $\mathrm{RCC}$ between patients infected with different leptospiral serovars. These findings suggest that haemoglobin and red cell counts may be useful in differentiating leptospiral serovars in suspected leptospirosis patients.

\section{CONFLICT OF INTEREST}

The authors declare that there is no conflict of interest.

\section{REFERENCES}

1. Turgut M, Sunbul M, Bayirli D, Bilge A, Leblebicioglu H, Haznedaroglu I. Thrombocytopenia complicating the clinical course of leptospiral infection. J Internat Res 2002; 30:535-540.

2. Dall'Antonia M, Sluga G, Whitfield S, Teall A, Wilson P, Krahé D. Leptospirosis pulmonary haemorrhage: a diagnostic challenge. Emerg Med J 2008; 25:51-52.

3. Alston JM, Brown HC. The Epidemiology of Weil's Disease (Section of Epidemiology and State Medicine). Proc R Soc Med 1939; 30:741-756.

4. Levett PN. Leptospirosis. Clin Microbiol Rev 2001; 14:296-326.

5. Hookey JV, Bryden J, Gatehouse L. The use of $16 \mathrm{~S}$ rDNA sequence analysis to investigate the phylogeny of Leptospiraceae and related spirochaetes. J Gen Microbiol 1993; 139:2585-2590
6. Slack AT, Symonds ML, Dohnt MF, Smythe LD. The epidemiology of leptospirosis and the emergence of Leptospira borgpetersenii serovar Arborea in Queensland, Australia, 1998-2004. Epidemiol Infect 2006; 134:1217-1225.

7. Esen S, Sunbul M, Leblebicioglu H, Eroglu C, Turan D. Impact of clinical and laboratory findings on prognosis in leptospirosis. Swiss Med Wkly 2004; 134:347-352.

8. Jauréguiberry S, Roussel M, Brinchault-Rabin G, Gacouin A, Le Meur A, Arvieux C, et al. Clinical presentation of leptospirosis: a retrospective study of 34 patients admitted to a single institution in metropolitan France. Clin Microbiol Infect 2005; 11:391-394.

9. Lopes AA, Costa E, Sacramento E. Lymphopenia in hospitalised cases of leptospirosis. Clin Microbiol Infect 2005; 11:857-858.

10. Ko AI, Reis MG, Ribeiro Dourado CM, Johnson WD, Riley LW. Urban epidemic of severe leptospirosis in Brazil. Lancet 1999; 354:820-825.

11. Tucunduva-de-Faria M, Calderwood MS, Athanazio DA, McBride AJA, Hartskeerl RA, Pereira MM, et al. Carriage of Leptospira interrogans among domestic rats from an urban setting highly endemic for leptospirosis in Brazil. Acta Tropica 2008; 108:1-5.

12. Craig SB, Graham GC, Burns MA, Dohnt MF, Smythe LD, McKay DB. Lymphopenia in leptospirosis. Ann Trop Med Parasitol 2009; 103:279-282.

13. Somers CJ, Al-Kindi S, Montague S, O'Connor R, Murphy PG, Jeffers M, et al. Erythroid hypoplasia associated with leptospirosis. J Infect 2003; 47:85-86.

14. McKenzie SB. Textbook of Hematology. $2^{\text {nd }}$ ed. Sydney: Williams \& Willkins; 1996.

15. Kaushansky K. Lineage specific hematopoietic growth factors. N Engl J Med 2006; 354:2034-2045. 